\title{
Validation of the General Self-Efficacy Scale among Qatari young women
}

\author{
A. Crandall, ${ }^{1}$ H.F. Abdul Rahim ${ }^{2}$ and K.M. Yount ${ }^{3}$
}

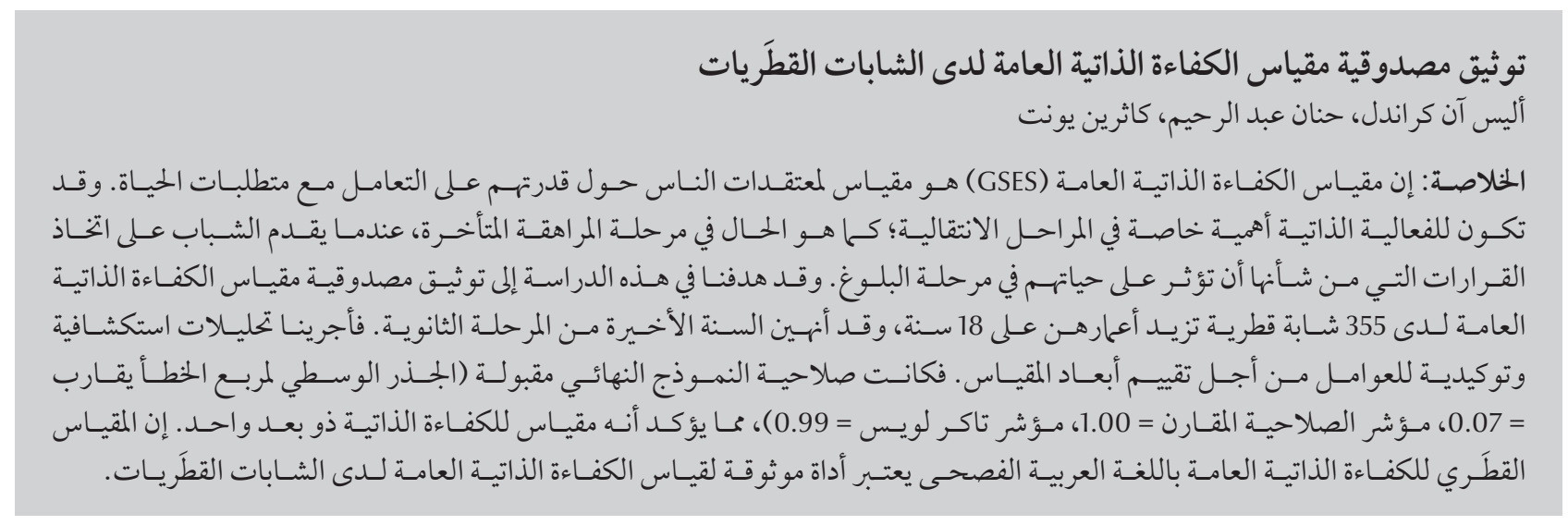

ABSTRACT The General Self-Efficacy Scale (GSES) is a measure of people's beliefs about their capacity to cope with life's demands. Self-efficacy may be particularly relevant in transitional stages such as in late adolescence, when young people make decisions that will impact their adult lives. In the present study, we aimed to validate an Arabic version of GSES among 355 Qatari young women aged 18+ years and finishing their final year of high school. We conducted exploratory and confirmatory factor analyses to assess the scale dimensionality. The final model fit was adequate (root mean square error of approximation $=0.07$, comparative fit index $=1.00$, TuckerLewis index $=0.99$ ), confirming a unidimensional self-efficacy measure. The Qatari Standard Arabic GSES is a reliable tool for measuring general self-efficacy among young Qatari women.

\section{Validation de l'Échelle d'efficacité personnelle générale auprès de jeunes femmes qataries}

RÉSUMÉ L'Échelle d'efficacité personnelle générale mesure la conviction des personnes à avoir la capacité de faire face aux aléas de la vie. Le sentiment d"efficacité personnelle peut être particulièrement pertinent lors de phases de transition telles que la fin de l'adolescence, lorsque les jeunes gens prennent des décisions qui affecteront leur vie d'adulte. Dans la présente étude, nous avions pour objectif la validation d'une version en langue arabe de l'échelle auprès de 355 jeunes femmes qataries âgées de 18 ans ou plus et en dernière année de secondaire. Nous avons mené des analyses factorielles exploratoires et de confirmation pour évaluer les dimensions de l'échelle. L'ajustement du modèle final était approprié (erreur quadratique moyenne de I'approximation = 0,07; indice comparatif d'ajustement $=1,00$; indice de Tucker-Lewis $=0,99$ ) confirmant une mesure unidimensionnelle du sentiment d'efficacité personnelle. L'Échelle d'efficacité personnelle en arabe standard du Qatar est fiable pour mesurer l'efficacité personnelle générale chez des jeunes femmes qataries.

${ }^{7}$ Hubert Department of Global Health, Emory University, Atlanta, Georgia, United States of America and Department of Health Science, Brigham Young University, Provo, Utah, United States of America. (Correspondence to A. Crandall: ali_crandall@byu.edu). ${ }^{2}$ Social and Economic Survey Research Institute; and Department of Health Sciences (College of Arts and Sciences), Qatar University, Doha, Qatar ${ }^{3}$ Hubert Department of Global Health and Department of Sociology, Emory University, Atlanta, Georgia, University States of America.

Received: 07/11/14; accepted: 01/09/15 


\section{Introduction}

Self-efficacy, a core aspect of socialcognitive theory, refers to "people's beliefs about their capabilities to exercise control over their own level of functioning and over events that affect their lives" (1). These beliefs influence a person's motivation and may be the most important factors for determining behaviour (2). Self-efficacy is not the objective ability of an individual, rather it captures an individual's perception of their performance capability (3). Those with high self-efficacy tend to select, create and transform their environmental circumstances more actively than those with lower levels of self-efficacy (4).

Self-efficacy is an under-studied area of research in Qatar and has important implications for young women as they transition into adulthood. Perceived self-efficacy is important in determining aspirations and behaviours such as those for work, schooling and family formation (5). For example, in Qatar, historically women who have been engaged in the labour force have been employed in "feminized" occupations (e.g. clerical jobs or jobs in education and health care) (6). Opportunities to engage in "non-traditional" occupations that have been historically staffed by men (e.g. engineering, technology and leadership positions) have been socially devalued $(6,7)$. However, based on social-cognitive theory, women with high self-efficacy could aspire to and achieve goals for non-traditional occupations, despite barriers that shape the larger environment.

The General Self-Efficacy Scale (GSES) was first developed in 1979 in German by Jerusalem and Schwarzer. The original 20-item scale was reduced to 10 items in 1981 and is now available in 33 languages (5). The scale is designed to assess a person's optimistic self-beliefs used to cope with life's demands; it does not assess coping and adaptation for specific behaviours. Selfefficacy is typically referenced in relation to specific tasks, but high self-efficacy on one task is thought to generalize to other tasks $(1,8,9)$.

The GSES has been used in numerous studies and has been validated as a unidimensional construct for adults (including adolescents) in several single- (10) and multi-country studies (8,11-14). An Arabic version of the scale has been validated in the Syrian Arab Republic among individuals aged $12-94$ years old $(8,12)$. Metric invariance and partial scalar invariance have been satisfied across countries $(13,14)$.

To our knowledge, the Qatari Standard Arabic version of the GSES has not been validated nor has it been validated specifically with a late adolescent and young adult population. Here, we assessed general self-efficacy among Qatari women in the 12th grade who were at least 18 years old. We hypothesized that the scale would be unidimensional in this population. If the scale were validated it would provide us with the opportunity to look at young women's self-efficacy as they transition into adulthood.

\section{Methods}

\section{Setting}

There is increasing recognition in Qatar, a nation of approximately 2 million people (15), that women's participation in the labour market is necessary to maintain its fast-growing economy. Currently, about $36 \%$ of women participate in the labour force, a figure which is low compared with neighbouring countries (6). Although their labour force participation is low, women outnumber men in undergraduate university enrolment by a scale of 3 to 1 (16). However, women disproportionately major in the arts and humanities, majors that are not in alignment with jobs in the fastest growing areas of the Qatari economy: telecommunications, transportation and business (6). Young women's general self-efficacy may impact their beliefs about their ability to perform in jobs that men historically have staffed, and thus it may play a strong role in young women's choice of occupation. The validation of the GSES among young women in Qatar is necessary in order to test in subsequent studies the relationship between young women's self-efficacy and their aspirations for education, work and marriage.

\section{Sample}

The participants were 369 female, Qatari students in the 12th grade of secondary school, ranging in age from 18-23 years. The students came from 29 schools throughout Qatar. All eligible women (enrolled in the 12th grade, at least 18 years old and never married) were invited to participate. Data collection was carried out in the schools via computer-assisted self-interview.

Before beginning the survey, the women provided their informed consent. They were told that the purpose of the survey was to learn how parents and other kin influence the participation of young women in the labour force. Respondents were not compensated for completing the survey.

Response rates varied by school, with a total response rate of approximately $59 \%$, based on the available school records for the total number of eligible students. Of the 369 participants, 14 did not respond to the selfefficacy questions; the final sample for this analysis included 355 Qatari young women. The average age of participants was 18.6 years and $79 \%$ of respondents' mothers and $82 \%$ of fathers had received at least some schooling.

\section{Measure}

The GSES comprises 10 items rated on a scale of 1 (not at all true) to 4 (exactly true) (5). Sample items include: "I can manage to solve difficult problems if I try hard enough" and "If I am in trouble, I can usually think of a solution". The scale was translated into Qatari Standard Arabic by a professional translator, 
and the translation was reviewed by 2 researchers.

\section{Data analysis}

To test the factor structure of the GSES among young women in Qatar, we conducted exploratory and confirmatory factor analyses with robust weighted least squares estimation using Mplus, version 7.17 (17). We performed the exploratory factor analyses on a random split-half sample $(n=178)$, running sequential 1-3 factor models. To compare exploratory factor analyses models, we conducted exploratory structural equation modelling and calculated the chi-squared difference test.

We then performed the confirmatory factor analyses on the other random split-half (to provide a subsample independent from the exploratory factor analyses subsample) (18). Adequate model fit was indicated by a comparative fit index (CFI) and Tucker-Lewis index $(\mathrm{TLI})>0.90$, a root mean square error of approximation (RMSEA) $<0.08$ (19) and theoretical interpretation.

\section{Results}

Table 1 shows the item mean scores for the exploratory factor analyses, confirmatory factor analyses and the full sample. Item means ranged from 2.69 to 2.98 in the full sample. The internal consistency for the total sample was $\alpha=0.95$. All items were left (negatively) skewed and had kurtosis $<3$, which is evidence of a light-tail distribution (the skewness and kurtosis results are available on request from the first author)

In the exploratory factor analyses, fit indices for the 1-, 2- and 3-factor models were all adequate based on the CFI and TLI, but poor based on the RMSEA. Chi-squared difference tests were computed to compare the 3 -factor and 2-factor models with the 1-factor model. Based on these tests, the 3-factor and 2-factor models fitted the data better than the 1-factor model (chisquared difference tests for the 3-factor model versus 1-factor model: $\chi^{2}=$ $266.58, P<0.001$; for the 2 -factor versus 1-factor model: $\chi^{2}=186.89, P<0.001$ ). However, the 2- and 3-factor models were not theoretically meaningful and several items had high cross-loadings (Table 2).

We chose to confirm the 1-factor model $(\mathrm{RMSEA}=0.23, \mathrm{CFI}=0.96$, TLI $=0.95)$ for the following reasons. First, we felt that the similarities in semantics among some items resulted in additional factors in the exploratory factor analyses solution that were not substantive latent variables. The factor structure might be better modelled by correlating the error terms on similar items in a 1-factor solution. A limitation of exploratory factor analyses is that correlated errors cannot be specified. Due to this limitation, the source of covariation among items (such as similarly worded indicators or method effects) may manifest as additional factors even though the covariation is not due to substantive latent variables (20). Secondly, factor loadings for each of the 10 items using a 1-factor model were high (> 0.75 ). Thirdly the eigenvalue for a 1 -factor structure was 7.62 while the 2 -factor eigenvalue was $<1.00$, indicating a 1 -factor structure. In confirmatory factor analyses, the model fit was also poor based on the

\begin{tabular}{|c|c|c|c|}
\hline \multirow[t]{3}{*}{ Items ${ }^{\mathrm{a}}$} & \multicolumn{3}{|c|}{ Mean (SD) scores } \\
\hline & $\begin{array}{l}\text { Exploratory factor } \\
\text { analysis }\end{array}$ & $\begin{array}{l}\text { Confirmatory } \\
\text { factor analysis }\end{array}$ & $\begin{array}{l}\text { Total sample } \\
\quad(n=355)\end{array}$ \\
\hline & $\begin{array}{l}\text { Subsample } \\
\qquad(n=178)\end{array}$ & $\begin{array}{l}\text { Subsample } \\
(n=177)\end{array}$ & \\
\hline A. I can manage to solve difficult problems if I try hard enough & $2.79(1.06)$ & $2.71(1.03)$ & $2.75(1.05)$ \\
\hline $\begin{array}{l}\text { B. If someone opposes me, I can find the means and ways to get } \\
\text { what I want }\end{array}$ & $2.69(1.07)$ & $2.69(1.04)$ & $2.69(1.06)$ \\
\hline C. It is easy for me to stick to my aims and accomplish my goals & $3.03(1.07)$ & $2.92(0.98)$ & $2.97(1.02)$ \\
\hline $\begin{array}{l}\text { D. I am confident that I could deal efficiently with unexpected } \\
\text { events }\end{array}$ & $2.98(1.00)$ & $2.93(0.98)$ & $2.95(0.99)$ \\
\hline $\begin{array}{l}\text { E. Thanks to my resourcefulness, I know how to handle } \\
\text { unforeseen situations }\end{array}$ & $2.89(0.96)$ & $2.76(0.98)$ & $2.83(0.97)$ \\
\hline F. I can solve most problems if I invest the necessary effort & $2.89(0.98)$ & $2.88(1.01)$ & $2.89(0.99)$ \\
\hline $\begin{array}{l}\text { G. I can remain calm when facing difficulties because I can rely } \\
\text { on my coping abilities }\end{array}$ & $2.89(1.02)$ & $2.80(1.04)$ & $2.85(1.03)$ \\
\hline $\begin{array}{l}\text { H. When I am confronted with a problem, I can usually find } \\
\text { several solutions }\end{array}$ & $2.93(0.93)$ & $2.86(1.01)$ & $2.90(0.97)$ \\
\hline I. If I am in trouble, I can usually think of a solution & $3.02(0.96)$ & $2.93(1.02)$ & $2.98(0.99)$ \\
\hline J. I can usually handle whatever comes my way & $2.93(0.89)$ & $2.84(1.00)$ & $2.88(0.95)$ \\
\hline
\end{tabular}

${ }^{a}$ Score range: $1-4$.

$S D=$ standard deviation 


\begin{tabular}{|c|c|c|c|c|c|}
\hline \multirow[t]{2}{*}{ Variable } & \multicolumn{2}{|c|}{ 2-factor model } & \multicolumn{3}{|c|}{ 3-factor model } \\
\hline & Factor 1 & Factor 2 & Factor 1 & Factor 2 & Factor 3 \\
\hline Items & \multicolumn{5}{|c|}{ Factor loadings } \\
\hline $\begin{array}{l}\text { A. I can manage to solve difficult problems if I try hard } \\
\text { enough }\end{array}$ & $0.963^{*}$ & -0.019 & $1.039^{*}$ & -0.080 & 0.000 \\
\hline $\begin{array}{l}\text { B. If someone opposes me, I can find the means and ways } \\
\text { to get what I want }\end{array}$ & $0.834^{*}$ & 0.046 & $0.826^{*}$ & 0.014 & 0.039 \\
\hline $\begin{array}{l}\text { C. It is easy for me to stick to my aims and accomplish my } \\
\text { goals }\end{array}$ & $0.682^{*}$ & $0.320^{*}$ & $0.583^{*}$ & 0.015 & $0.424^{*}$ \\
\hline $\begin{array}{l}\text { D. I am confident that I could deal efficiently with } \\
\text { unexpected events }\end{array}$ & $0.440^{*}$ & $0.553^{*}$ & 0.173 & -0.003 & $0.870^{*}$ \\
\hline $\begin{array}{l}\text { E. Thanks to my resourcefulness, I know how to handle } \\
\text { unforeseen situations }\end{array}$ & $0.219^{*}$ & $0.742^{*}$ & 0.003 & $0.515^{*}$ & $0.449^{*}$ \\
\hline F. I can solve most problems if I invest the necessary effort & $0.155^{*}$ & $0.800^{*}$ & 0.090 & $0.678^{*}$ & $0.204^{*}$ \\
\hline $\begin{array}{l}\text { G. I can remain calm when facing difficulties because I } \\
\text { can rely on my coping abilities }\end{array}$ & -0.007 & $0.874^{*}$ & 0.024 & $0.903^{*}$ & -0.060 \\
\hline $\begin{array}{l}\text { H. When I am confronted with a problem, I can usually } \\
\text { find several solutions }\end{array}$ & 0.066 & $0.916^{*}$ & 0.113 & $0.903^{*}$ & -0.018 \\
\hline I. If I am in trouble, I can usually think of a solution & -0.010 & 0.932 & $-0.020^{*}$ & 0.913 & $0.036^{*}$ \\
\hline J. I can usually handle whatever comes my way & -0.020 & $0.926^{*}$ & -0.118 & $0.819^{*}$ & $0.219^{*}$ \\
\hline Correlations & \multicolumn{5}{|c|}{ Correlation coefficients } \\
\hline Factor 1 with Factor 2 & \multicolumn{2}{|c|}{$0.666^{*}$} & \multicolumn{3}{|c|}{$0.704^{*}$} \\
\hline Factor 1 with Factor 3 & \multicolumn{2}{|c|}{$\mathrm{n} / \mathrm{a}$} & \multicolumn{3}{|c|}{$0.630^{*}$} \\
\hline Factor 2 with Factor 3 & \multicolumn{2}{|c|}{$\mathrm{n} / \mathrm{a}$} & \multicolumn{3}{|c|}{$0.775^{*}$} \\
\hline Analysis & \multicolumn{5}{|c|}{ Model fit indices } \\
\hline RMSEA & \multicolumn{2}{|c|}{0.164} & \multicolumn{3}{|c|}{0.135} \\
\hline $\mathrm{CFI}$ & \multicolumn{2}{|c|}{0.986} & \multicolumn{3}{|c|}{0.993} \\
\hline TLI & \multicolumn{2}{|c|}{0.976} & \multicolumn{3}{|c|}{0.983} \\
\hline
\end{tabular}

$* P<0.05$.

Items would have been dropped in the 2-factor model due to factor loadings $>0.30$ on both factors. This would have left factor 1 with only 2 items (items A and B) and factor 2 with 6 items. Factors should have at minimum of 3 items; Items would have been dropped in the 3-factor model due to factor loadings $>0.30$ on more than 1 factor. Factor 1 would have had only 2 items (items A and B), factor 2 would have had 5 items (items F-J) and factor 3 would have had only 1 item (item D). RMSEA = root mean square error of approximation; $C F I=$ comparative fit index; $T L I=$ Tucker-Lewis index; $n / a=$ not applicable.

RMSEA (0.17), but was good based on the CFI (0.97) and TLI (0.96).

We next correlated 9 residual error terms on similarly worded items. The first 3 items of the GSES, included semantics that focused on the problemsolving aspects of self-efficacy; the last 4 items included semantics relating to the coping aspect of self-efficacy. In the first 3 items (A-C), the semantics focus on an individual's ability to problem solve due to their determination or effort (item A: "manage to solve" and "try hard enough"; item B: "find means and ways"; item C: "stick to my aims"). The last 4 items $(\mathrm{G}-\mathrm{J})$ focus on the respondent's awareness of their coping abilities or belief that "I can cope with this" (item G: "rely on coping abilities"; item H: "find solutions"; item I: "think of solution"; item J: "handle"). Items $D, E$, and $F$ are a mix of these 2 aspects of self-efficacy. The correlation of these error terms was based on reviewing the semantics of the items for similarities along with assessing the modification indices generated in Mplus. These modification indices verified our study of item similarity and dissimilarity. Thus, it made substantive sense to correlate the residual error terms of the first 3 items and of the last 4 items (19). The resulting model fit was adequate $(\mathrm{RMSEA}=0.07, \mathrm{CFI}=1.00, \mathrm{TLI}=$
0.99), confirming a unidimensional self-efficacy measure.

Table 3 displays the results of the Geomin-rotated 1-factor exploratory factor analyses model and the 1-factor confirmatory factor analyses model. Factor loadings ranged from 0.79 to 0.95 in the EFA and from 0.69 to 0.97 (with 9 residual error terms on similar items correlated) in the CFA.

\section{Discussion}

The current study provides evidence that the Arabic version of the GSES is a reliable tool to measure general 


\begin{tabular}{|c|c|c|}
\hline Variable & $\begin{array}{c}\text { Exploratory factor } \\
\text { analysis } \\
(n=178)\end{array}$ & $\begin{array}{c}\text { Confirmatory factor } \\
\text { analysis } \\
(\boldsymbol{n}=177)\end{array}$ \\
\hline Items & \multicolumn{2}{|c|}{ Factor loadings } \\
\hline A. I can manage to solve difficult problems if I try hard enough ${ }^{b}$ & $0.833^{*}$ & $0.687^{*}$ \\
\hline B. If someone opposes me, I can find the means and ways to get what I want ${ }^{b}$ & $0.787^{*}$ & $0.716^{*}$ \\
\hline C. It is easy for me to stick to my aims and accomplish my goals ${ }^{b}$ & $0.874^{*}$ & $0.847^{*}$ \\
\hline D. I am confident that I could deal efficiently with unexpected events & $0.898^{*}$ & $0.965^{*}$ \\
\hline E. Thanks to my resourcefulness, I know how to handle unforeseen situations & $0.896^{*}$ & $0.930^{*}$ \\
\hline F. I can solve most problems if I invest the necessary effort & $0.904^{*}$ & $0.949^{*}$ \\
\hline $\begin{array}{l}\text { G. I can remain calm when facing difficulties because I can rely on my coping } \\
\text { abilities }\end{array}$ & $0.854^{*}$ & $0.805^{*}$ \\
\hline H. When I am confronted with a problem, I can usually find several solutionsb & $0.954^{*}$ & $0.834^{*}$ \\
\hline I. If I am in trouble, I can usually think of a solution ${ }^{b}$ & $0.908^{*}$ & $0.788^{*}$ \\
\hline J. I can usually handle whatever comes my way ${ }^{b}$ & $0.882^{*}$ & $0.766^{*}$ \\
\hline Analysis & \multicolumn{2}{|c|}{ Model fit indices } \\
\hline RMSEA & 0.231 & 0.069 \\
\hline $\mathrm{CFI}$ & 0.962 & 0.996 \\
\hline TLI & 0.952 & 0.993 \\
\hline
\end{tabular}

${ }^{*} P<0.05$.

${ }^{a}$ Results with 9 residual error terms on similar items correlated; ${ }^{b}$ The residual error terms of items $A, B$, and C and of items $G, H, I$ and $J$ were correlated in confirmatory factor analysis.

RMSEA = root mean square error of approximation; $C F I=$ comparative fit index; $T L I=$ Tucker-Lewis index

self-efficacy among young Qatari women in secondary school. In line with other studies and our hypothesis, this analysis supports a unidimensional measure of self-efficacy $(8,12)$.

Item mean scores, which ranged from 2.69 to 2.98, were similar to those of other countries in the Eastern Mediterranean Region (8), including the Syrian Arab Republic (2.48 to 3.16) and the Islamic Republic of Iran (2.78 to 3.47), and also those in the United States of America (USA) (2.59 to 3.33). The range in item means in Qatar was narrower, however, perhaps reflecting our more homogenous sample, comprising only women aged 18-23 years who were in their final year of high school. The internal consistency of the scale among Qatari young women (0.95) was comparable, but higher than in other countries where the scale has been validated. For example, in the scale validation that Schwarzer et al. carried out in 14 countries the internal consistency ranged from 0.78 in the Greek version to 0.91 in the Japanese version (12). Item mean scores and the internal consistency of the scale further suggests that self-efficacy is a valid construct among Qatari young women.

Young women's self-efficacy may influence their choice of career. Assessing the relationship between young women's self-efficacy and their career aspirations is an important next step to understand young Qatari women's aspirations for schooling as well as for work. To our knowledge, this question has not been studied previously in Qatar, and few studies have assessed this question internationally. In a study of 123 university students in the USA, researchers assessed the association between young women's task-specific self-efficacy and their choice of a leadership versus a team-member career (21). Young women with higher self-efficacy were more likely to choose leadership careers over team-member careers than were young women with lower selfefficacy. While task-specific self-efficacy is more likely to predict career choices, general self-efficacy may also be predictive of young women's perceived career options. Further research that explores this association and that validates a taskspecific self-efficacy scale in Qatar is warranted.

One limitation of the current study was that the response rate in the schools was lower than previous school-based studies in Qatar and elsewhere in the region $(22,23)$, although it was comparable to some school-based surveys carried out in the USA $(24,25)$. The survey was conducted near the end of the school year, when students were taking examinations, which may have contributed to response rates lower than in previous surveys. This was a census sample with differential rates of 
participation by schools, and we do not have information about those who did not choose to participate and whether they had significantly different characteristics from those who did participate. These limitations notwithstanding, the results validate the GSES as a unidimensional measure of self-efficacy and a reliable tool for measuring general selfefficacy among young women in Qatar.

\section{Acknowledgements}

We express our gratitude and appreciation to the entire research staff for their dedication to this work and to the study participants, without whom this research would not have been possible. We also express our appreciation to Yuk Fai Cheong of Emory University for his guidance on the data analysis.
Funding: This study was made possible by a NPRP award (NPRP-5626-5-089, K.M. Yount lead principle investigator and H.F. Abdul Rahim co-lead principle investigator) from the Qatar National Research Fund (a member of The Qatar Foundation). The statements made herein are solely the responsibility of the authors.

Competing interests: None declared.

\section{References}

1. Bandura A. Perceived self-efficacy in cognitive development and functioning. Educ Psychol. 1993;28(2):117-48.

2. Bandura A. Social learning theory. New York (NY): General Learning Press; 1977.

3. Zimmerman BJ. Self-efficacy: An essential motive to learn. Contemp Educ Psychol. 2000 Jan;25(1):82-91. PMID:10620383

4. Bandura A. Exercise of human agency through collective efficacy. Curr Dir Psychol Sci. 2000;9(3):75-8.

5. Schwarzer R, Jerusalem M. Generalized self-efficacy scale. In: J. Weinman SW, Johnston M, editors. Measures in health psychology: a user's portfolio. Causal and control beliefs. Windsor, United Kingdom: NFER-Nelson, 1995: 35-7.

6. Qatar national development strategy 2011-2016. Doha: Qatar General Secretariat for Development Planning; 2011:175.

7. Abdalla IA. Relationships of career self-efficacy and personality variables with status of academic and career choice among Arab students. Psychol Rep. 1994;75(3, Pt 2):1571-82.

8. Scholz U, Doña BG, Sud S, Schwarzer R. Is general self-efficacy a universal construct? Psychometric findings from 25 countries. Eur J Psychol Assess. 2002;18(3):242-51.

9. Sherer M, Maddux JE, Mercandante B, Prentice-Dunn S, Jacobs B, Rogers RW. The Self-Efficacy Scale: construction and validation. Psychol Rep. 1982;51(2):663-71. PMID:7089151

10. Leung DYP, Leung AYM. Factor structure and gender invariance of the Chinese General Self-Efficacy Scale among soon-to-be-aged adults. J Adv Nurs. 2011 Jun;67(6):1383-92. PMID:21129011

11. Luszczynska A, Scholz U, Schwarzer R. The general selfefficacy scale: multicultural validation studies. J Psychol. 2005 Sep;139(5):439-57. PMID:16285214

12. Schwarzer R. General perceived self-efficacy in 14 cultures [Internet]. Berlin: Freie Universität Berlin; 1999 (http://userpage. fu-berlin.de/ health/world14.htm, accessed 24 September 2015).

13. Schwarzer R, Bäßler J, Kwiatek P, Schröder K, Zhang JX. The assessment of optimistic self- beliefs: comparison of the German, Spanish, and Chinese versions of the General Selfefficacy Scale. Appl Psychol. 1997;46(1):69-88.
14. Teo T, Kam C. A measurement invariance analysis of the general self-efficacy scale on two different cultures. J Psychoed Assess. 2014 Dec;32(8):762-7.

15. Total population 31 July 2014. Doha: Qatar Ministry of Development Planning and Statistics; 2014 (http://www.qsa.gov. qa/eng/index.htm, accessed 24 September 2015).

16. Qatar University factbook 2012-2013. Doha, Qatar: Qatar University, Office of Institutional Planning and Development; 2103.

17. Mplus user's guide [program]. Los Angeles: Muthen \& Muthen; 1998-2012.)

18. Bandalos DL, Finney SJ. Factor analysis: exploratory and confirmatory. In: Hancock GR, Mueller RO, editors. The reviewer's guide to quantitative methods in the social sciences. Abingdon, United Kingdom: Routledge; 2010. p. 93-114.

19. Brown TA. Confirmatory factor analysis for applied research. New York (NY): Guilford Press; 2006.

20. Brown TA, Moore MT. Confirmatory factor analysis. In: Hoyle $\mathrm{R}$, editor. Handbook of structural equation modeling. New York (NY): Guilford Press; 2012.

21. Dickerson A, Taylor MA. Self-limiting behavior in women selfesteem and self-efficacy as predictors. Group Organ Manage. 2000;25(2):191-210.

22. Education study 2012: curriculum report. Doha: Qatar University, Social and Economic Survey Research Institute; 2014:27.

23. Kelishadi R, Heshmat R, Motlagh ME, Majdzadeh R, Keramatian K, Qorbani M, et al. Methodology and early findings of the third survey of CASPIAN study: A national school-based surveillance of students' high risk behaviors. Int J Prev Med. 2012 Jun;3(6):394-401. PMID:22783465

24. Eaton DK, Kann L, Kinchen S, Shanklin S, Flint KH, Hawkins J, et al. Youth risk behavior surveillance-United States, 2011. MMWR Surveill Summ. 2012 Jun 8;61(4):1-162. PMID:22673000

25. Ethier KA, Dittus PJ, DeRosa CJ, Chung EQ, Martinez E, Kerndt PR. School-based health center access, reproductive health care, and contraceptive use among sexually experienced high school students. J Adolesc Health. 2011 Jun;48(6):562-5. PMID:21575814 